\title{
MUDANÇAS EM PROJETOS ARQUITETÔNICOS E A FINANCEIRIZAÇÃO DO CAPITAL EM BELÉM, PA
}

\author{
BUILDING DESIGN CHANGES AND FINANTIALIZATION OF CAPITAL IN BELEM, PA, BRAZIL
}

\author{
Dayana Marinho Mota de \\ Santana 1 \\ (D) José Júlio Ferreira Lima ${ }^{2}$ \\ Raul da Silva Ventura Neto ${ }^{3}$ \\ 'Universidade Federal do Pará, Belém, \\ Pará, Brasil, motajayana@gmail.com \\ 2 Universidade Federal do Para, Belém, \\ Pará, Brasil, jjlima@ufpa.br \\ 3 Universidade Federal do Para, Belém, \\ Pará, Brasil, netoventuraraul@gmail.com
}

Contribuição dos autores:

JMMS: conceituação, curadoria de dados, análise formal, investigação, metodologia, visualização, escrita - rascunho original. JJFL: conceituação, análise formal, aquisição de financiamento, metodologia, administração de projetos, supervisão, visualização, escrita - rascunho original. RSVN: validação, escrita - rascunho original, escrita - revisão e edição.

\section{Fomento: Conselho Nacional de}

Desenvolvimento Científico e Tecnológico. Declaração de conflito: nada foi declarado.

Editor Responsável:

Sidney Piochi Bernardini $\mathbb{D}$

\begin{abstract}
Resumo
O objetivo deste artigo é analisar os mecanismos que conectam as racionalidades financistas às alterações ocorridas no processo de concepção do projeto arquitetônico de empreendimentos imobiliários em Belém, PA, após a sanção da legislação de patrimônio de afetação em 2004. Para tal, investigam-se as metodologias de Custeio-meta, com foco na Análise de Valor (AV), para o desenvolvimento da Viabilidade Econômica e Financeira. A revisão teórica feita leva à análise de estudos de projetos arquitetônicos e à compreensão da interferência da viabilidade econômica e financeira na concepção de dois empreendimentos imobiliários construídos na Área de Expansão de Belém por empresas diferentes, uma de capital local e outra de capital aberto, tendo ambas utilizado o software Viabil nos projetos arquitetônicos. Os resultados indicam convergências entre a proporções métricas nos projetos, a distribuição de ambientes e perímetros de envoltórias das torres, o que sugere a absorção pela empresa de capital local de inovação trazida por empresas de capital aberto, contribuindo também para o entendimento de alterações no modo de morar na escala urbana em Belém.
\end{abstract}

Palavras-chave: Financeirização. Custeio-meta. Incorporação imobiliária. Projeto arquitetônico. Viabilidade econômica e financeira. Belém PA.

\begin{abstract}
This article aims to analyze the mechanisms that link financial rationality and changes in designing the architectural design process of real estate projects in Belém, PA, after the sanction of the allocation heritage legislation in 2004. Therefore, it is examined the application of Target Costing methodologies that uses Value Analysis (VA) as an important technical basis for Economic and Financial Feasibility development. A theoretical review leads to an analysis of the application of this methodology for studies of architectural projects and to an understanding of the interference of economic and financial feasibility in setting up two real estate projects built in the Belém Expansion Area by different companies, one with local capital and the other with financial capital, both using Viabil software in architectural projects. The results indicate convergences between metric proportions in the projects, the distribution of rooms, and the perimeters of the towers' envelopes, which suggests the absorption by the local capital company of innovation brought by financial based firms, also contributing to the understanding of the changes in the way of living at the urban scale in Belém.

Keywords: Financing, Target costing. Real estate market. Architectural design. Economic and financial viability. Belém PA.
\end{abstract}

How to cite this article:

SANTANA, J. M. M. de; LIMA, J. J. F.; VENTURA NETO, R. da S. Mudanças em projetos arquitetônicos e a financeirização do capital em Belém, PA. PARC Pesquisa em Arquitetura e Construção, Campinas, SP, v. 12, p. e021019, 2021. DOI:

http://dx.doi.org/10.20396/parc.v12i00.8660768

\section{Introdução}

A implementação da legislação de patrimônio de afetação no Brasil, em 2004, é associada à caminhada do mercado brasileiro em direção à financeirização (SANFELICI, 2013). Embora tenha sido uma alteração paulatina, ao longo de 14 anos, modificações legais criaram o nexo entre o mercado imobiliário e o mercado financeiro, provocando a necessidade de que as empresas do setor imobiliário, na busca por maior eficiência 
nos processos de gestão de custos e lucros dos empreendimentos, mudassem o ciclo produtivo das edificações de mercado (AMATO, 2009).

No caso específico da cidade de Belém, as modificações observadas na produção do espaço urbano revelam tendências oriundas do processo de financeirização na produção imobiliária recente na Área de Expansão Urbana (AEU). Nos últimos 5 anos, vem ocorrendo a introdução da tipologia de condomínio multifamiliar verticalizado, planejado em etapas. Assim, este artigo tem por objetivo analisar os mecanismos que conectam as racionalidades financistas às alterações em projetos arquitetônicos de empreendimentos imobiliários em Belém, após a sanção da legislação de patrimônio de afetação em 2004. A atenção se volta para as alterações verificadas em projetos residenciais multifamiliares lançadas por empresas incorporadoras de atuação nacional, associadas ou não a empresas locais em virtude das modificações legais no Brasil em direção à financeirização da produção imobiliária. Desse modo, examinam-se primeiro modificações em estudos de viabilidade econômica e financeira de empreendimentos imobiliários, por meio da utilização das metodologias de Custeio-meta (CM) e Análise de Valor (AV) ${ }^{(1)}$ associadas à governança corporativa, assim como o exame de seus possíveis resultados em projetos arquitetônicos de empreendimentos localizados na AEU de Belém. O resultado desse exame indica forte influência das racionalidades financistas inerentes ao software utilizado nos projetos arquitetônicos dos empreendimentos imobiliários analisados. A contribuição do artigo é a analisar a financeirização da produção urbana em um contexto distinto das grandes cidades onde já há numerosos estudos (FIX, 2011; RUFINO, 2012; RIBEIRO, DINIZ, 2017;

A contribuição do artigo é analisar os efeitos da financeirização do espaço urbano e do projeto arquitetônico no contexto de uma metrópole periférica brasileira. A literatura atual têm se dedicado a evidenciar como o avanço da financeirização nos principais circuitos imobiliários do país representou alterações nas esferas de controle de empresas tradicionalmente reservadas às elites nacionais (FIX, 2011), bem como impulsionou novas dinâmicas de concentração e centralização (RUFINO, 2012) que contribuíram para novas racionalidades no projeto (ANITELLI; TRAMONTANO, 2016) na gestão do canteiro de obras (BARAVELLI, 2015) sem, entretanto, alterar formas arcaicas de dependência com subsídios públicos (SHIMBO, 2016). Autores como Rolnik (2015) e Fernandez e Aalbers (2019), apontam para uma forma de financeirização subordinada nos países do Sul Global, como uma forma contemporânea de um desenvolvimento desigual e combinado, moldado pela financeirização dos países do Norte Global, que promove contornos específicos aos processos de financeirização da habitação. A depender de como foram estruturas os sistemas financeiros de cada país o processo de "colonização" de instituições, privadas ou públicas, por racionalidades associadas ao mundo das finanças, pode promover diferentes graus de autonomia sobre a classe proprietária do país (BARDET; COULONDRE; SHIMBO, 2020;). No caso brasileiro, mesmo que seja possível visualizar algumas vertentes do conceito de financeirização em pesquisas empreendidas nos últimos anos, é possível notar um vínculo estreito entre a viabilidade da financeirização do mercado habitacional e os fundos públicos, o que apresenta como uma das principais características do fenômeno no país (KLINK; SOUZA, 2017).

Foi evidenciado em Belém, que determinadas práticas mercadológicas, próprias de empresas de capital aberto, haviam sido disseminadas no processo de produção do espaço construído local, como, por exemplo, a articulação entre diferentes empresas com intuito de "criar localização" (VENTURA NETO, 2012). Isso pode ser atestado pelo desenvolvimento e implantação do primeiro shopping center na AEU, empreendimento viabilizado por meio de uma joint venture entre as empresas Cyrela Brazil Realty (CBR) 
com atuação nacional, a Status Construções (SC) de formação local e a Aliansce Shopping Centers (ALSC). Esse empreendimento materializa a "simbiose" entre agentes imobiliários voltados para a criação da centralidade que ratificaria e viabilizaria uma demanda residencial no local, e que levou ao lançamento de dois empreendimentos imobiliários no seu entorno: o Masterplan Parque Jardins (MPJ) da CBR e o Condomínio Chácaras Montenegro (CCM) da SC.

Os dois empreendimentos constituem casos de estudo por se tratar de empreendimentos de localização, público-alvo e estratégia de inserção no mercado semelhantes, possibilitando uma análise comparativa a respeito do processo de produção de empreendimentos viabilizados por empresas de origem de capital distintas, já que a SC é uma empresa de capital local, assim denominada por não se valer de capital de giro ou crédito junto a bancos nacionais e a CBR uma empresa listada no Novo Mercado da Bolsa de Valores de São Paulo (BM\&FBovespa), ou seja, uma empresa de capital aberto com ofertas públicas de ações.

A aparente utilização de uma mesma estratégia de preparação do ambiente mercadológico por parte da CBR e da SC levou ao questionamento a que este artigo busca responder: até que ponto uma empresa de capital local estaria utilizando racionalidades próprias de empresas de capital aberto em seus processos de produção? $\mathrm{O}$ artigo explora a questão sobre como a (des)regulamentação brasileira em direção à financeirização vem interferindo no processo de concepção de projetos arquitetônicos de condomínios multifamiliares verticais na cidade de Belém, PA, considerando um aumento na participação de capital portador de juros na reprodução ampliada de capital incorporador.

Sugere-se pertinente de analisar os processos projetuais por meio da utilização de softwares de apoio pelo setor da construção, capazes de auxiliar na gestão de grande quantidade de variáveis envolvidas no processo de concepção de projetos arquitetônicos, bem como na inter-relação com o processo orçamentário. Essa necessidade resultou no desenvolvimento de softwares articulados com a metodologia de Custeio-meta, criados com o objetivo de agilizar o processo de ajuste dos estudos de viabilidades econômicas e financeiras dos empreendimentos imobiliários, principalmente no que tange às fases de Análise de Valor (AV) (LEE, 1994). É válido observar que, segundo os sites das empresas que vendem e descrevem esses softwares, eles também são capazes de gerar, de maneira rápida, relatórios financeiros exigidos pelas normas de governança corporativa imputadas pelo novo mercado financeiro (VIABIL, 2020), as quais demandam maior controle dos custos e dos lucros para que os níveis de rentabilidade exigidos pelos investidores financeiros sejam garantidos. Mesmo que o objetivo final dos investidores esteja voltado para a ampliação de renda diferencial, ou mesmo renda de monopólio por meio da "criação de localização" - que seria a face da produção do espaço urbano enquanto efeitos da financeirização -, há que se atentar para os processos internos da produção imobiliária para melhor entendimento do tema.

Acredita-se que, a partir de 2007, o capital financeiro que entra no circuito imobiliário de Belém leva as empresas constituídas localmente a operar com racionalidades similares às de capital aberto, mesmo em casos de empreendimentos de capital exclusivamente local. Esta modificação teria alterado as empresas para as quais passa a ser obrigatório o cumprimento das normas de governança corporativa para obterem resultados econômicos mais positivos em um contexto onde elementos da financeirização da produção urbana vem alterando enormemente a paisagem local, além de levar a mudanças nos projetos arquitetônicos, foco deste artigo. 


\section{Discussão bibliográfica}

Viabilidade econômica e financeira do projeto arquitetônico em tempos de financeirização

A dependência de fatores econômicos e de viabilidade financeira provoca a necessidade da utilização de métodos racionais que auxiliem na tomada de decisão, antes do efetivo comprometimento de custos que, no caso de empreendimentos imobiliários, são de grande porte. Uma incorporação imobiliária só acontece caso o resultado da análise de fatores econômicos e financeiros seja positivo (LIMA JÚNIOR et.al., 2011), processo conhecido como análise de Viabilidade Econômico-Financeira de empreendimentos imobiliários (Figura 1).

O mercado imobiliário tradicionalmente se utilizava do método de custeio conhecido como mark-up. Segundo tal método, após a elaboração do projeto arquitetônico do empreendimento, a empresa orçava os custos do mesmo, embutia o lucro definido pela empresa com base em Taxas Internas de Retorno (TIR) e lançava o Valor Geral de Venda (VGV) do imóvel no mercado imobiliário (BADIN, 2005), o que é próprio da utilização de capital financeiro. Após a conclusão da etapa de (des)regulamentação brasileira em direção à financeirização e a efetiva criação de inúmeras possibilidades de entrada de capital financeiro no mercado imobiliário, os fatores financeiros passaram a ter maior peso, tornando o método mark-up insuficiente para empresas que abriram capital na bolsa. Isso, porque métodos mais avançados de custeio são próprios da racionalidade financeira para a análise da viabilidade do empreendimento, bem como para permitir maior transparência - questão fundamental na governança corporativa, exigida pelo mercado financeiro (AMATO, 2009).

Figura 1 - Mapa conceitual de fatores que afetam a incorporação imobiliária

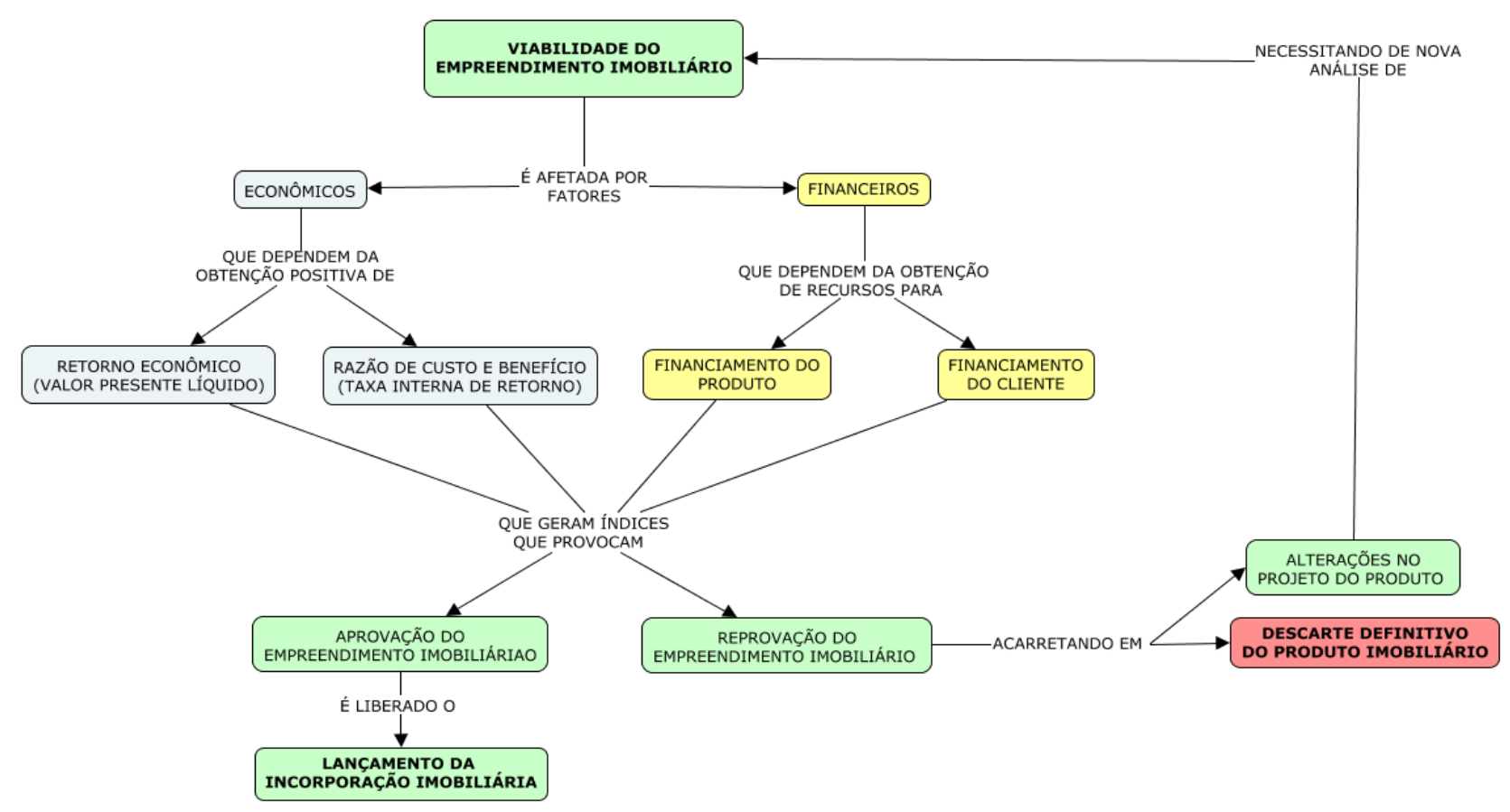

Fonte: os autores.

Em função dessas necessidades, o mercado imobiliário apropria-se da metodologia conhecida como Custeio-meta, invertendo o raciocínio do custeio tradicional (BADIN, 2005). A nova metodologia, basicamente, estipula as margens de lucros mínimas 
desejadas pelos investidores e o valor de venda aceito no mercado, tratando o desenvolvimento do produto como um instrumento de alcance das metas estabelecidas pela viabilidade econômica e financeira do mesmo. O projeto do produto passa a ser um "resultado matemático" que viabiliza atingir metas de custo e lucro, diferente das características de projetos arquitetônicos desenvolvidos por meio do método mark-up, situação na qual o projeto era desenvolvido antes do custeio, o que aparentemente possibilitava a utilização de processos decisórios mais vinculados a questões de ordem criativa e funcional do que de custo.

\section{A importância do Projeto de Produto na análise do processo produtivo imobiliário}

Em contexto capitalista, o projeto, segundo Badin (2005, p.37), “é uma organização temporária arranjada para alcançar uma determinada meta, durante um certo período, e com determinado custo". Ele estima que, em média, $80 \%$ do custo de produção de um novo produto é comprometido pelas decisões tomadas na etapa do seu desenvolvimento. Por essa razão, o projeto de produto tem um papel estratégico, já que é um processo que une necessidades de mercado e potencial de produção da empresa, permitindo que sejam atingidas as metas da organização através da sua capacidade de reduzir custos de execução, de melhorar a qualidade do produto e de inserir as expectativas dos clientes.

O custo de qualquer mudança na execução de um produto é tanto maior quanto mais avançada for a fase na qual for realizada, o que evidencia a importância do projeto para o planejamento de custos, já que nesta etapa os ajustes no empreendimento podem ser realizados sem grandes impactos (ROZENFELD, 1997). Portanto, o projeto de produto, de maneira geral, tem um papel estratégico.

Especificamente no caso de desenvolvimento de projetos arquitetônicos, esse papel estratégico é ainda mais evidente, tendo em vista a quantidade de variáveis envolvidas na concepção e no custeio do mesmo. O processo de projetar uma edificação seria similar ao de Sistemas Caóticos altamente sensíveis, nos quais eventos aparentemente insignificantes dão origem a consequências indesejadas (SIMON; BALDWIN; NEWTON, 1994, p. 447). Por isso, "a inter-relação entre todos os fatores que devem ser levados em consideração é a essência do problema de projeto, e não a análise de cada fator separadamente" (LAWSON, 2005, p.60) (2). Não se pode deixar de mencionar, então, que esse caráter de sistema complexo do Projeto Arquitetônico seja exacerbado quando seu desenvolvimento é atrelado ao custeio.

Segundo Formoso e Tzorzopoulos (2001), a atividade criativa de projetar em arquitetura pode ser dividida em duas fases: compreender um problema e desenvolver uma solução. No processo de planejamento de custos, o ideal é que ambas as fases sejam desenvolvidas simultaneamente, já que é necessário que o produto desenvolvido seja viável econômica e financeiramente desde as etapas iniciais de desenvolvimento do projeto arquitetônico. Por essa razão, a integração dos estudos financeiros a todas as fases do desenvolvimento do projeto arquitetônico é fundamental.

Para fins de desenvolvimento de projetos de empreendimentos imobiliários, "compreender um problema" significa realizar pesquisa de mercado a fim de identificar as preferências do consumidor. Para isso, adota-se para análise a metodologia da Preferência Declarada do Consumidor. A consonância entre o Programa de Necessidades do Projeto e os anseios do consumidor irá influenciar diretamente na velocidade de venda do mesmo. No entanto, um Programa de Necessidades econômica e financeiramente eficiente não se resume a atender a todos os anseios do cliente potencial. Em casos de projetos desenvolvidos por meio de softwares embasados na metodologia de Custeio-meta - metodologia capaz de controlar diversas variáveis 
envolvidas no processo sistemático "caótico" -, a preferência do consumidor nem sempre será considerada, uma vez que o nível de controle existente permite a clara percepção de como o desejo do consumidor não é a única variável que interfere na rentabilidade. Portanto, os anseios dos consumidores são levados em conta tanto quanto impactem positivamente na rentabilidade do empreendimento (FREITAS, 2000). Logo, o Projeto Arquitetônico e, mais especificamente, a definição do programa de necessidades e pré-dimensionamento interferem em larga proporção na Viabilidade Econômica e Financeira dos Empreendimentos Imobiliários desenvolvida por meio da Metodologia de Custeio-meta.

A metodologia de custeio-meta como abordagem de estudo de viabilidade econômica financeira de empreendimentos imobiliários

A Viabilidade Econômica e Financeira de um projeto é relacionada com a variável "tempo", em virtude de a rentabilidade variar exponencialmente com o mesmo (LIMA JÚNIOR; MONETTI; DE ALENCAR, 2011). Isso significa dizer que um projeto também pode ser ou não viável, de acordo com a previsão de velocidade de retorno financeiro. Por esta razão, a pesquisa de mercado é largamente aplicada, já que um projeto será tão rapidamente vendido quanto mais for ao encontro das expectativas dos consumidores. Em virtude disso, o mercado imobiliário, influenciado pela regulamentação brasileira em direção à financeirização, tem utilizado a metodologia de Custeio-meta, pois esta contempla de maneira eficiente as variáveis que influenciam na velocidade de venda e rentabilidade do produto (FREITAS, 2000).

A metodologia de Custeio-meta foi desenvolvida no Japão, após a Segunda Guerra Mundial. O gerenciamento de custos nas indústrias japonesas foi visto como oportunidade para a reconstrução do país. Essa metodologia, em certa medida, se trata de aperfeiçoamento de uma metodologia de custeio conhecida como Análise de Valor (AV) - uma metodologia norte-americana, desenvolvida durante a II Guerra Mundial por engenheiros da Empresa General Eletric, que consistia na pesquisa de materiais que estivessem disponíveis para o mercado civil e que possuíssem custos mais baixos, possibilitando a substituição de itens escassos e onerosos durante anos de guerra (FREITAS, 2000).

No Japão, a interdisciplinaridade foi aliada à $A V$, combinando profissionais do planejamento, marketing, engenharia, finanças e produção, organizando equipes com objetivo de diminuir custos e aumentar qualidade (ONO, 2003). Por meio do refinamento da metodologia de $\mathrm{AV}$, essas equipes criaram a metodologia de Custeiometa, que tem como propósito assegurar as margens de lucro desejadas pela organização por meio da realização do planejamento do custo. Trata-se de técnica usada para administrar o custo como insumo no processo de desenvolvimento do produto e não como resultado, como era praticado tradicionalmente pelo método mark-up.

É fundamental conhecer as variáveis diretamente vinculadas à metodologia de Custeiometa para que seja possível compreender a escolha das variáveis utilizadas no Estudo de Caso apresentado a seguir. O Custeio-meta tem como principais variáveis: o preço de venda, o lucro-meta e o custo-meta. O preço de venda é determinado pelo mercado e o lucro-alvo pela empresa. Já o custo-meta é obtido pela diferença do preço de venda em relação à lucratividade desejada, ou seja, este custo está vinculado com o ambiente externo (mercado) e o ambiente interno (empresa/investidores).

O Custeio-Meta é uma metodologia considerada adequada ao desenvolvimento de produtos por empresas de capital aberto na Bolsa de Valores em função de permitir que a primeira variável a ser levada em conta seja o lucro-meta. Nela, os investidores definem um lucro-meta, após a subtração desse valor do preço-meta, quando se chega 
ao custo-meta - dando início, então, ao desenvolvimento de um projeto considerado adequado à realidade de mercado e aos anseios dos investidores. Para que o projeto seja considerado viável, são comparados custo-meta e custo contábil do projeto, conhecido como "custo flutuante". Quando o "custo flutuante" estimado for igual ou inferior ao custo-meta, significa que, se este produto for executado, não só terá o seu custo-meta alcançado, mas também o lucro-meta. Para alguns autores, o custo-meta seria a diferença entre o custo-meta e o "custo flutuante", valor este conhecido como GAP. Portanto, a fabricação do produto seria aprovada no caso de o GAP ser igual ou maior que zero. No caso de a fabricação não ser aprovada $(G A P<0)$, antes de descartar o projeto, é feita uma análise mais detalhada da especificação de materiais do projeto, a fim de identificar onde pode haver cortes de custos, ou até para a revisão geral do projeto a fim de verificar quais as prioridades do cliente e cortar o que para eles seria indiferente ou menos desejado. Para tanto, a metodologia de Custeio-meta utiliza-se da $\mathrm{AV}$, objetivando racionar custos (ONO,2003). Na AV, é verificado se o "custo flutuante" é menor ou igual ao custo-meta (ou se o GAP é maior, menor ou igual a zero), podendo o produto ser aprovado ou considerado definitivamente inviável depois de análises feitas (Quadro 1 e Figura 2).

Quadro 1 - Avaliação de custos estimados, permitidos e GAPs para decisão de produção

\begin{tabular}{|c|c|c|c|}
\hline Classificação de Custos & Valor & Resultado do GAP & Fases a seguir \\
\hline Custo Estimado & 100 & \multirow{3}{*}{$\mathrm{GAP}=0$} & \multirow{3}{*}{ Fase 3} \\
\hline Custo Máx. Permitido & -100 & & \\
\hline GAP & 0 & & \\
\hline Custo Estimado & 100 & \multirow{3}{*}{$\mathrm{GAP}<0$} & \multirow{3}{*}{ Fase 2 ou 3} \\
\hline Custo Máx. Permitido & -120 & & \\
\hline GAP & -20 & & \\
\hline Custo Estimado & 100 & \multirow{3}{*}{$\mathrm{GAP}>0$} & \multirow{3}{*}{ Fase 2} \\
\hline Custo Máx. Permitido & -80 & & \\
\hline GAP & 20 & & \\
\hline
\end{tabular}

Nota: As fases mencionadas acima constam da Figura 1 abaixo. Fonte: Ansari (1997), adaptado por Ono (2003).

O "custo flutuante" é calculado com base nas estimativas de valorização do produto projetado, objetivando reduzi-lo até o "custo máximo permitido", com base nas diversas alternativas possíveis de fabricação e/ou de utilização de materiais. Portanto, a principal ferramenta para a adequação do "custo flutuante" ao "custo máximo permitido" conforme a metodologia de $\mathrm{AV}$, por meio da qual identificam-se melhor as vantagens e desvantagens competitivas para a produção (3).

Entende-se que a $A V$ tenha por objetivo identificar de maneira eficiente os custos desnecessários em um produto, entendendo como tal tudo o que não agrega qualidade, utilidade, durabilidade, estética ou anseios do consumidor. Ou seja, custos que não agregam valor, custos que ao serem eliminados não diminuem o valor percebido pelo cliente no uso do produto ou serviço. Analogamente, o custo que não deve ser eliminado é o agregador de valor, ou seja, aquele que sendo extinto reduz o valor do produto ou serviço, aos olhos dos consumidores (ONO, 2003).

No entanto, não se trata apenas de agradar ao consumidor, mas de utilizar de maneira econômica e financeiramente eficiente o conhecimento sobre as preferências do mesmo, já que o objetivo maior do Projeto, no sistema capitalista, é alcançar os níveis de rentabilidade exigidos pelos investidores.

A AV utiliza dois conceitos fundamentais: valor e função. $O$ valor é determinado pelas preferências declaradas pelo consumidor e a função determinada por meio da definição de programa de necessidades, definidos com base na $A V$ das preferências. 


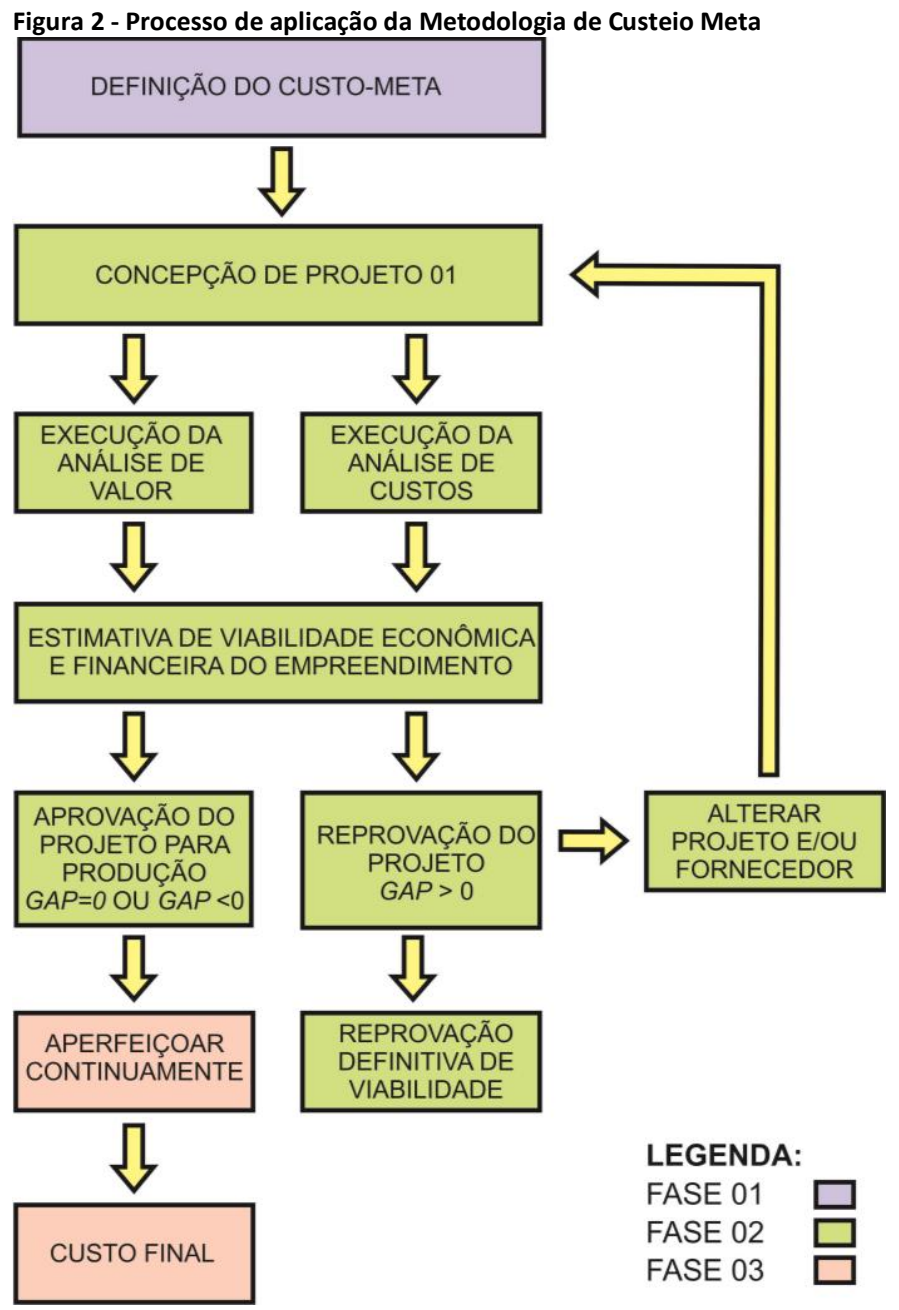

Fonte: Ono (2003), adaptado pelos autores.

Em suma, a AV, no caso do projeto arquitetônico, é fundamental não apenas para a geração do programa de necessidades e pré-dimensionamento do mesmo, mas para o processo de especificação de materiais de acabamento. No estudo a seguir, no entanto, deu-se particular atenção ao processo decisório referente ao programa de necessidades e, mais especificamente, ao pré-dimensionamento das unidades habitacionais e dos condomínios. Acredita-se que, já que o cliente poderá alterar os materiais de acabamento interno do imóvel após o recebimento, tem limitada sua capacidade de alterar o arranjo interno em planta oriundo do programa de necessidades e a distribuição de área, principalmente em projetos verticalizados.

Portanto, enquanto parte da metodologia para chegar a um Custeio-meta, a AV é bastante relevante no processo de definição de Programas de Necessidades de Projetos Arquitetônicos, uma vez que nesta fase projetual é possível eliminar o que não gera valor na percepção do cliente, e eliminar o que gera ônus aos níveis de rentabilidade, além de avaliar o impacto de ambos na Viabilidade econômica e financeira do empreendimento imobiliário.

Mudanças do processo decisório na concepção do projeto arquitetônico provocadas pela adoção da metodologia de custeio-meta

A diferença da composição de custos unitários de produção entre os diferentes ambientes é utilizada pela AV como meio para atingir o valor do custo-meta, durante o estudo de viabilidade econômica e financeira do empreendimento (FREITAS, 2000). A 
percepção da diferença entre custos unitários de produção de cada ambiente, correlacionada ao resultado da pesquisa de mercado, gera variáveis utilizadas para o desenvolvimento de um projeto arquitetônico que seja considerado viável econômica e financeiramente. A possibilidade de utilizar essas variáveis com eficiência provoca as principais alterações no processo de concepção de projetos arquitetônicos, uma vez que pode direcionar a composição de programas de necessidades, que, atrelada ao conhecimento do custo unitário de cada ambiente, leva ao direcionamento de decisão correspondente ao pré-dimensionamento do projeto.

Informações sistematizadas por Freitas (2000), mostram que o percentual de custo por metro quadrado de ambientes em relação à área total de uma unidade habitacional é variável. Enquanto o coeficiente de custo de construção do metro quadrado de uma sala é de 1,136, o de um banheiro ou de uma cozinha corresponde a quase o dobro: 2,078. Isso ocorre pela evidente diferença de custo unitário de cada ambiente, já que um ambiente que necessite ter suas paredes revestidas terá um custo unitário maior do que um ambiente que não necessite disso, ou até um ambiente que tenha menos extensão de paredes, como é o caso de varandas e sacadas.

O processo decisório na concepção de Projetos Arquitetônicos desenvolvidos por meio da Metodologia do Custeio-meta é bastante influenciado pela AV feita a partir de resultados encontrados nas Pesquisas de Mercado. Isto porque essa análise é utilizada como ponto de partida para a geração dos Programas de Necessidades mais adequados aos objetivos econômicos e financeiros do empreendimento. São eleitos os anseios dos consumidores que tenham um impacto positivo na viabilidade e/ou que sejam de grande importância para estabelecer uma velocidade de venda aceitável.

Os valores percentuais obtidos por Freitas (2000) indicam preferências a partir da escolha de dois "atributos contraditórios", devendo o avaliador da pesquisa optar por um deles (Coluna 3 do Quadro 4). Os resultados apresentados por Freitas foram analisados com o objetivo de criticar o processo decisório na fase de geração de Programa de Necessidades e Pré-dimensionamento de Projetos Arquitetônicos imersos na metodologia de Custeio-meta. Para tal, no Quadro 2 as colunas 4 e 5 apresentam posicionamentos próprios dos autores desse artigo, sobre os resultados do estudo de Freitas.

Sugere-se que o impacto sobre a rentabilidade do empreendimento seja indiferente nas questões 1 e 6 . Isso quer dizer que, para efeito de custo unitário médio de produção, é indiferente a informação sobre a preferência do consumidor em potencial relativamente aos dois "atributos contraditórios" expostos. Ou seja, independentemente da decisão de projeto tomada, não haverá acréscimo ou decréscimo nos custos de produção. Sendo assim, nesses casos, o projetista tende a considerar a preferência do cliente em função de não onerar o projeto e agregar valor ao imóvel a ser projetado.

Já nas questões $2,3,5,9$ e 10, sugere-se que haverá um impacto positivo sobre a rentabilidade do empreendimento, pois ao considerar a preferência do cliente em relação aos dois "atributos contraditórios expostos", haverá uma redução do custo unitário médio da produção da unidade habitacional a ser projetada. Ou seja, acatar a preferência do cliente acarretaria em aumento da rentabilidade do empreendimento pela redução de custos do metro unitário médio de produção e do aumento simultâneo de velocidade de venda devido a consonância do projeto com os anseios dos clientes em potencial. Já as questões 4,7 e 8 , teriam impacto negativo sobre a rentabilidade do empreendimento, uma vez que os dois "atributos contraditórios" expostos levariam a 
um acréscimo no custo unitário médio de produção da unidade habitacional a ser projetada.

Além da indicação das questões, o trabalho de Freitas (2004) sugere que há indicações que podem ser tomadas como exemplares. O tamanho do imóvel e a maneira como se dá a distribuição da área entre os ambientes internos não interferem no VGV do mesmo, já que esse valor será proporcional à quantidade de área vendida e será estipulado em função do valor unitário do metro quadrado no mercado, na localidade e nicho de mercado do empreendimento. No entanto, a forma como a área do imóvel é distribuída interfere no custo total do imóvel, tendo em vista, entre outros fatores, a diferença entre o custo do metro quadrado construído de cada tipo de ambiente, distribuição essa definida durante a etapa de AV da Metodologia de Custeio-meta.

Quadro 2 - Questões empregadas na análise de preferência no processo de concepção do projeto arquitetônico

\begin{tabular}{|c|c|c|c|c|}
\hline \multicolumn{2}{|r|}{ Questões Pesquisadas } & \multirow{2}{*}{$\begin{array}{c}\begin{array}{c}\text { Percentual de } \\
\text { preferência entre } \\
\text { clientes }\end{array} \\
64 \% \\
\end{array}$} & \multirow{3}{*}{$\begin{array}{c}\text { Impacto sobre a } \\
\text { rentabilidade } \\
\text { Indiferente }\end{array}$} & \multirow{3}{*}{$\begin{array}{c}\text { Conduta projetual } \\
\text { Considerar }\end{array}$} \\
\hline \multirow{2}{*}{ Questão 1} & Aumento de $1 \mathrm{~m}^{2}$ na área íntima & & & \\
\hline & Aumento de $1 \mathrm{~m}^{2}$ na área da sala de jantar & $36 \%$ & & \\
\hline \multirow{2}{*}{ Questão 2} & Aumento de $1 \mathrm{~m}^{2}$ na área social & $72 \%$ & \multirow{2}{*}{ Positivo } & \multirow{2}{*}{ Considerar } \\
\hline & Aumento de $1 \mathrm{~m}^{2}$ na área de serviços & $28 \%$ & & \\
\hline \multirow{2}{*}{ Questão 3} & Aumento de $1 \mathrm{~m}^{2}$ no banheiro & $27 \%$ & \multirow{2}{*}{ Positivo } & \multirow{2}{*}{ Considerar } \\
\hline & Aumento de $1 \mathrm{~m}^{2}$ no quarto & $73 \%$ & & \\
\hline \multirow{2}{*}{ Questão 4} & Aumento de $1 \mathrm{~m}^{2}$ da sala & $27 \%$ & \multirow{2}{*}{ Negativo } & \multirow{2}{*}{ Desconsiderar } \\
\hline & Espaço para mesa na cozinha & $73 \%$ & & \\
\hline \multirow{2}{*}{ Questão 5} & Sala sem varanda & $41 \%$ & \multirow{2}{*}{ Positivo } & \multirow{2}{*}{ Considerar } \\
\hline & Sala com varanda & $59 \%$ & & \\
\hline \multirow{2}{*}{ Questão 6} & Lavabo & $55 \%$ & \multirow{2}{*}{ Indiferente } & \multirow{2}{*}{ Considerar } \\
\hline & Segunda suíte & $45 \%$ & & \\
\hline \multirow{2}{*}{ Questão 7} & Varanda & $48 \%$ & \multirow{2}{*}{ Negativo } & \multirow{2}{*}{ Desconsiderar } \\
\hline & Closet & $52 \%$ & & \\
\hline \multirow{2}{*}{ Questão 3} & Quarto sem varanda & $74 \%$ & \multirow{2}{*}{ Negativo } & \multirow{2}{*}{ Desconsiderar } \\
\hline & Quarto com varanda & $26 \%$ & & \\
\hline \multirow{2}{*}{ Questão 9} & Grandes quartos e menos suítes & $88 \%$ & \multirow{2}{*}{ Positivo } & \multirow{2}{*}{ Considerar } \\
\hline & Pequenas Suítes & $12 \%$ & & \\
\hline \multirow{2}{*}{ Questão 10} & Despensa & $74 \%$ & \multirow{2}{*}{ Positivo } & \multirow{2}{*}{ Considerar } \\
\hline & Lavabo & $26 \%$ & & \\
\hline
\end{tabular}

Fonte: Freitas (2004), alterado pelos autores.

A velocidade de venda impacta efetivamente na rentabilidade do empreendimento, tendo em vista o impacto exponencial na variável tempo. Por essa razão, é necessário que o projetista considere não só o impacto da conduta no que diz respeito ao custo unitário médio de produção do imóvel, mas também o impacto dessa conduta na velocidade de venda do imóvel. Ou seja, se as preferências dos consumidores em potencial não provocassem grandes acréscimos de custos, os projetistas deveriam considerar tais posicionamentos no processo decisório de concepção do projeto arquitetônico, já que a presença dos atributos preferidos pelos mesmos acarretaria em maior velocidade de venda e, consequentemente, maior rentabilidade.

Por essa razão, em situações em que os percentuais sejam muito diferentes entre um atributo e outro, a preferência do consumidor talvez não seja considerada, embora o projetista possa criar soluções no sentido de minimizar os possíveis acréscimos de custo ocorridos no caso de considerar a preferência. Sugere-se que um exemplo disso seja o que é perguntado na questão 4. Ao aumentar a área de cozinha na unidade habitacional para a inserção de uma mesa no layout, ocorre acréscimo no custo unitário médio de produção do imóvel. Isso porque o custo metro quadrado de produção de uma cozinha é maior do que o de uma sala. No entanto, sendo o aumento de área desejado na cozinha para a utilização de uma área de refeições, o projetista pode criar soluções 
projetuais que permitam diminuir o impacto nos custos, como determinar que a parede próxima à mesa da cozinha não seja revestida. Desta forma, um acelerador de velocidade de venda pode ser viabilizado, mesmo que, à primeira visa, o impacto nos custos seja negativo.

O contrário também pode ocorrer. Quando a diferença percentual da preferência do consumidor potencial entre os "atributos contraditórios" não for grande, é possível que a conduta seja a de reduzir o custo unitário médio de produção. Isso porque a pouca diferença existente entre os percentuais encontrados nesse item indica certa indiferença do consumidor em relação à essa questão. Na questão 7 , onde $48 \%$ dos consumidores preferem a varanda a um closet, trocar a área de varanda por área de closet causa acréscimo no custo do empreendimento. Este é um caso no qual a conduta do projetista talvez seja optar pela varanda, reduzindo o custo médio unitário de produção do imóvel, já que considerar a preferência do consumidor talvez não gere impacto nenhum na velocidade de venda do imóvel, em função da diferença de apenas 4 pontos percentuais entre uma opção e outra, além de demonstrar indiferença dos consumidores quanto à essa troca.

A metodologia de Custeio-meta, portanto, permite integrar por meio da etapa de AV as variáveis relativas ao custo e os processos decisórios do projeto arquitetônico. Por essa razão, a metodologia foi utilizada como base para o desenvolvimento de softwares de viabilidade econômica e financeira de empreendimentos imobiliários, como o software Viabil, utilizado para a análise de viabilidade econômica e financeira dos produtos utilizados como objeto dessa pesquisa.

\section{Metodologia}

A metodologia da pesquisa consistiu no estudo de casos de empreendimentos construídos em Belém, Pará. Foram selecionados os empreendimentos Condomínio Chácaras Montenegro e o Masterplan Parque Jardins, localizados na AEU de Belém, tendo como justificativa o fato de apresentarem tipologia e visarem a atender a nichos de mercado semelhantes, além de, como dito, terem sido viabilizados por empresas de diferentes origens de capital - a SC, local e a CBR de capital aberto.

Os dois empreendimentos tiveram processos semelhantes no desenvolvimento dos projetos arquitetônicos, pois tanto a CBR quanto a SC utilizaram o software Viabil na realização dos estudos de viabilidade econômica e financeira dos empreendimentos imobiliários (VIABIL, 2018). O Viabil é um software para o desenvolvimento de estudos de viabilidade econômica e financeira de empreendimentos imobiliários bastante utilizado no mercado. Foi desenvolvido pela Empresa BDK Solutions, especialista em criar sistemas e soluções que auxiliem profissionais na tomada de decisão e gestão de negócios. Segundo o site da empresa, o software Viabil possui "uma base conceitual e matemática", constantemente atualizada para que possa "acompanhar as mudanças do setor de incorporação e construção" (VIABIL, 2018). O software pode ser utilizado nas principais etapas da incorporação, contendo 4 módulos diferentes: "Módulo Terrenos", "Módulo Viabilidade Análise de Cenários", "Módulo Viabilidade Acompanhamento" e "Módulo Análise de Propostas". O módulo com maior relevância para fins de análise é o "Módulo Viabilidade Análise de Cenário", já que propicia a troca de informações do projeto arquitetônico com as informações financeiras, econômicas e de mercado. O módulo é dividido nos seguintes temas: Viabilidade (com informações relativas à configuração do empreendimento e ao respectivo preço de venda por tipologia da unidade, bem como do terreno, incluindo seu custo); Obra (refere-se à distribuição de custos físico-financeiros, configuração e indicadores para análise do projeto arquitetônico); Financeiro (inclui aspectos ligados a índices econômicos, taxas 
de juro e de administração e informações sobre exigências de fontes de financiamento); Perfil de venda (ligado ao tempo de lançamento e velocidade de vendas junto a potenciais perfis de clientes); Perfil Periódicos (no qual se compara curvas e análise da propaganda, pré-incorporação e pós-obra); e Informações Complementares referentes ao acompanhamento do negócio durante sua execução.

A metodologia de análise dos projetos arquitetônicos que possam configurar mudanças entre os dois empreendimentos levou ao estudo de subcondomínios que compõem cada um dos empreendimentos. No caso do CCM, os subcondomínios apresentam-se de modo bastante semelhantes entre si, portanto, foram comparados ao subcondomínio Jardim de Provence, que possui um porte físico compatível e se trata do único dos subcondomínios do MPJ finalizado até o momento de realização da pesquisa (Figura 3).

$\mathrm{Na}$ escala da edificação, elegeu-se como parâmetro de comparação o tipo de torre do subcondomínio Jardim de Provence que contém unidades habitacionais de $92 \mathrm{~m}^{2}$ e $66 \mathrm{~m}^{2}$, para que fosse comparada com o edifício de padrão único do CCM. Isto, porque essa torre guarda mais semelhanças com a torre padrão do CCM quanto à área das unidades habitacionais, diferente da outra torre existente no subcondomínio Jardim de Provence. Definidos os objetos a serem analisados, foram realizadas medições nos desenhos dos projetos nas escalas dos subcondomínios, incluindo a torre e as unidades habitacionais componentes das torres. Para essa etapa metodológica, foram utilizados desenhos em escala obtidos nas empresas construtoras (STATUS CONSTRUÇÕES, 2010; CYRELA BRAZIL REALTY, 2011). As medições feitas forneceram a base para cotejamento com as variáveis constantes nos módulos do software Viabil. Tal opção metodológica justificase pela percepção de que tais variáveis relacionadas aos projetos arquitetônicos influenciariam na composição do custo unitário médio e, consequentemente, na rentabilidade dos empreendimentos imobiliários.

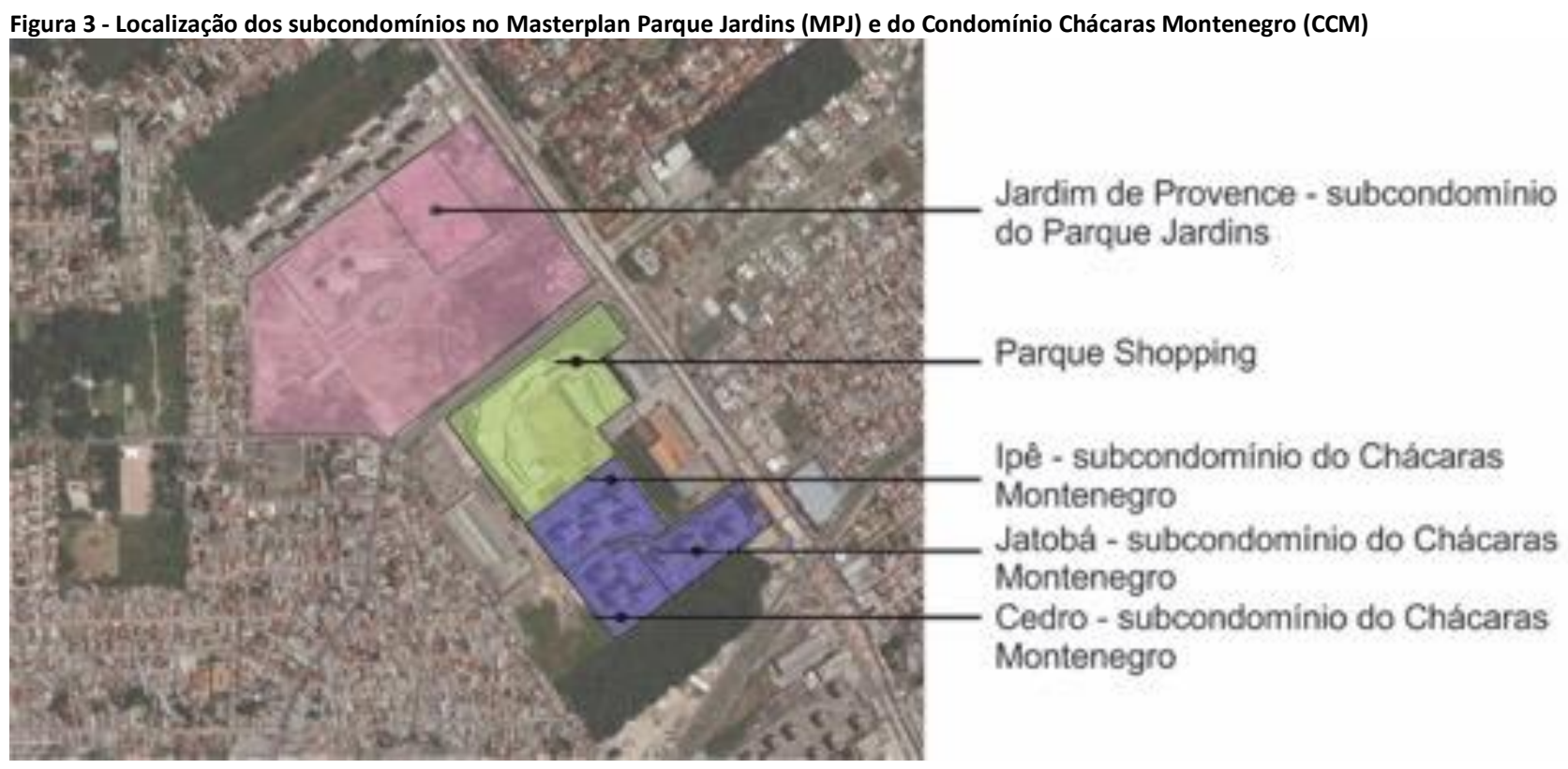

Fonte: Elaborado pelos autores com base em Google Earth, 2018.

O conhecimento das racionalidades da Metodologia de Custeio-meta, utilizadas no desenvolvimento do software Viabil, foi considerado na análise dos dados geométricos extraídos dos projetos. Em função de impactarem fortemente na viabilidade econômica e financeira, foram escolhidas variáveis de análise referentes a proporções geométricas, como áreas, perímetros e suas relações, determinantes para a concepção do partido 
arquitetônico e pré-dimensionamento das unidades habitacionais, pavimentos-tipo e ocupação do lote pelas torres.

A escolha das variáveis elencadas a seguir se deve à percepção de que estas influenciariam na composição do custo unitário médio e, consequentemente, na rentabilidade dos empreendimentos imobiliários (Quadro 3).

Analisar as coincidências geométricas entre os projetos, as quais são relativas a variáveis relacionadas com os indicadores do software Viabil, contribui para ratificar a hipótese de que a utilização desse software possa alterar as tomadas de decisão no processo de concepção do Projeto Arquitetônico de empreendimentos, contribuindo para a geração de um padrão de produção de espaço fortemente influenciado pela financeirização, independentemente de a incorporadora ter ou não capital aberto.

Quadro 3 - Identificação de variáveis e relações analisadas nos estudos de caso

\begin{tabular}{|c|c|c|}
\hline Escala de Análise & Variáveis & Redação \\
\hline Subcondomínio & $\begin{array}{l}\text { área dos subcondomínios } \\
\text { total de área privativa dos subcondomínios }\end{array}$ & $\begin{array}{l}\text { total de área privativa dos subcondomínio / área dos } \\
\text { subcondomínios }\end{array}$ \\
\hline \multirow{6}{*}{ Torre } & $\begin{array}{c}\text { área do pavimento tipo das torres } \\
\text { área do pavimento tipo das torres sem sacada }\end{array}$ & $\begin{array}{l}\text { área do pavimento tipo das torres / área da circulação } \\
\text { comum dos pavimentos tipo das torres }\end{array}$ \\
\hline & $\begin{array}{c}\text { área da circulação comum dos pavimentos tipo } \\
\text { torres } \\
\text { área privativa do pavimento tipo das torres }\end{array}$ & \multirow{2}{*}{$\begin{array}{c}\text { perímetro das torres sem sacada / área do pavimento tipo as } \\
\text { torres sem sacada } \\
\text { número de unidades habitacionais por pavimento tipo / } \\
\text { número de elevadores }\end{array}$} \\
\hline & perímetro das torres & \\
\hline & perímetro das torres sem sacada & \multirow{3}{*}{$\begin{array}{l}\text { área privativa do pavimento tipo das torres / número de } \\
\text { elevadores }\end{array}$} \\
\hline & número de elevadores & \\
\hline & $\begin{array}{l}\text { número de unidades habitacionais por } \\
\text { pavimento tipo }\end{array}$ & \\
\hline \multirow{7}{*}{ Unidade Habitacional } & $\begin{array}{l}\text { área total da unidade habitacional } \\
\text { área do setor social }\end{array}$ & área total seca / área total da unidade habitacional \\
\hline & $\begin{array}{c}\text { área do setor íntimo } \\
\text { área do setor de serviços } \\
\end{array}$ & área total molhada / área total da unidade habitacional \\
\hline & $\begin{array}{l}\text { área total seca } \\
\text { área total molhada }\end{array}$ & área total de sacada / área total da unidade habitacional \\
\hline & $\begin{array}{l}\text { área total de sacada } \\
\text { perímetro total de alvenaria }\end{array}$ & $\begin{array}{l}\text { perímetro total de alvenaria / área total da unidade } \\
\text { habitacional }\end{array}$ \\
\hline & perímetro de alvenaria revestida externamente & $\begin{array}{l}\text { perímetro total de alvenaria revestida externamente / área } \\
\text { total da unidade habitacional }\end{array}$ \\
\hline & $\begin{array}{c}\text { perímetro de alvenaria compartilhada com } \\
\text { outra unidade habitacional } \\
\text { área dos ambientes }\end{array}$ & \multirow{2}{*}{$\begin{array}{l}\text { perímetro total de alvenaria revestida internamente / área } \\
\text { total da unidade habitacional } \\
\text { perímetro de alvenaria compartilhada com outra unidade } \\
\text { habitacional / perímetro total de alvenaria da unidade } \\
\text { habitacional }\end{array}$} \\
\hline & $\begin{array}{c}\text { perímetro dos ambientes } \\
\text { perímetro total de alvenaria revestida } \\
\text { internamente }\end{array}$ & \\
\hline
\end{tabular}

\section{Resultados}

O CCM é um empreendimento multifamiliar verticalizado, lançado no ano de 2010, localizado no Km 04 da Av. Augusto Montenegro. Foi planejado por etapas, nas quais foram lançados três subcondomínios: Jatobá, Cedro e Ipê. Os dois primeiros são compostos por quatro torres e o último, por cinco torres, conforme pode ser verificado na Figura 4. Os três subcondomínios encontram-se construídos e entregues.

Assim como o empreendimento já mencionado, o Masterplan Parque Jardins foi desenvolvido sob o regime de Patrimônio de Afetação. Foi lançado no ano de 2011 pela $\mathrm{CBR}$, em parceria com a construtora local Síntese. O empreendimento é divulgado como um bairro planejado incorporado com seis subcondomínios multifamiliares verticais, um subcondomínio de uso misto e um de uso comercial. O subcondomínio utilizado para 
comparação com os do CCM é o Subcondomínio Jardim de Provence, composto por quatro torres de 12 pavimentos implantadas conforme ilustrado na Figura 4.

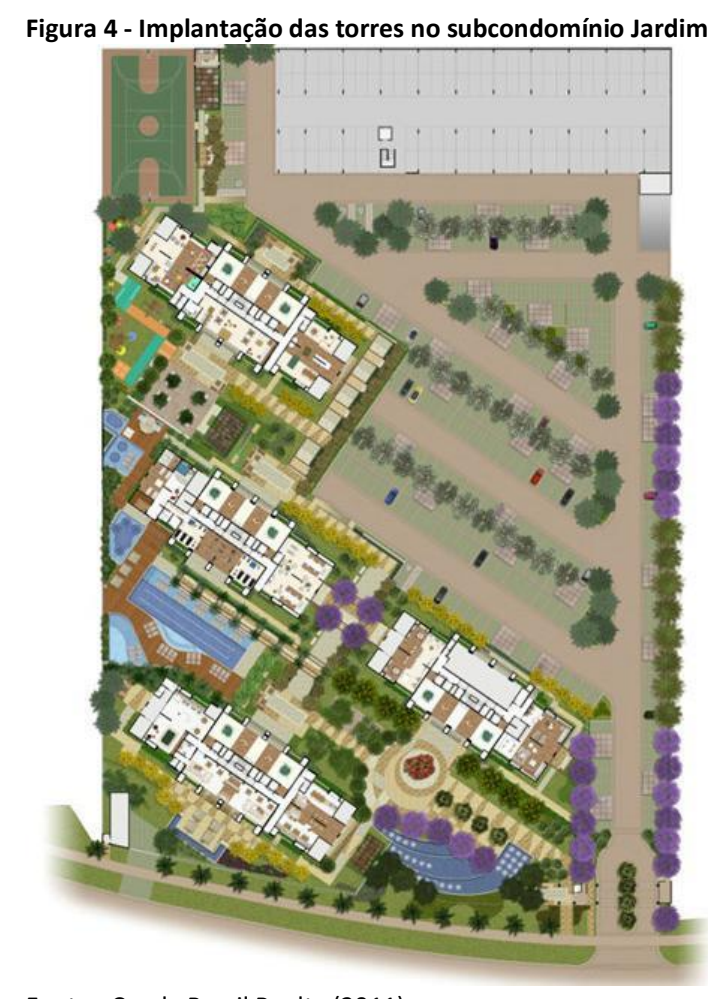

Fonte: Cyrela Brazil Realty (2011).

Após dividir a área do terreno dos subcondomínios do CCM e do Jardim de Provence pelo total de área privativa de cada um deles, obteve-se o valor aproximado do coeficiente de aproveitamento dos mesmos. Conforme pode ser verificado no Quadro 4, a média dos coeficientes de aproveitamento dos subcondomínios do CCM é muito próxima do coeficiente de aproveitamento do subcondomínio Jardim de Provence.

Quadro 4 - Coeficientes de aproveitamento dos terrenos dos subcondomínios analisados.

\begin{tabular}{|c|c|c|c|c|}
\hline Subconcomínio/ Condomínio & $\begin{array}{c}\text { Área do terreno } \\
(\mathbf{m} \mathbf{2})\end{array}$ & $\begin{array}{c}\text { Área privativa } \\
\text { construída (m2) }\end{array}$ & $\begin{array}{c}\text { Coeficiente de } \\
\text { Aproveitamento }\end{array}$ & $\begin{array}{c}\text { Média dos } \\
\text { subcondomínios }\end{array}$ \\
\hline Jatobá / Chácaras Montenegro & $13.938,00$ & $21.427,00$ & 0.54 \\
\hline Cedro.1 Chácaras Montenegro & $13.858,00$ & $21.427,00$ & 1.55 \\
\hline Ipê1 Chácaras Montenegro & 19.107 .00 & $26.843,00$ & 1.40 \\
\hline Jardim de Provence / Parque Jardins & $18.825,00$ & $28.416,00$ & 1,51 & 1,51 \\
\hline
\end{tabular}

Fonte: medições elaboradas pelos autores, a partir de arquivos de desenhos de plantas baixas dos empreendimentos de Status Construções (2010) e Cyrela Brazil Realty (2011).

Na escala de edificação, cada um dos subcondomínios do CCM contou com a implantação de torres de padrão único, compostas por térreo mais 11 pavimentos. $O$ pavimento tipo, conforme pode ser verificado na Figura 5 é dividido em 6 apartamentos, sendo dois de $68 \mathrm{~m}^{2}, 2$ de $79 \mathrm{~m}^{2}$ e dois de $88 \mathrm{~m}^{2}$. Cada uma das torres conta com hall de entrada, um elevador social e um elevador de serviço (Figura 5). Além disso, as torres possuem acabamento externo em revestimento cerâmico. 
Figura 5 - Planta Baixa do Pavimento Tipo das Torres implantadas no empreendimento Chácaras Montenegro.

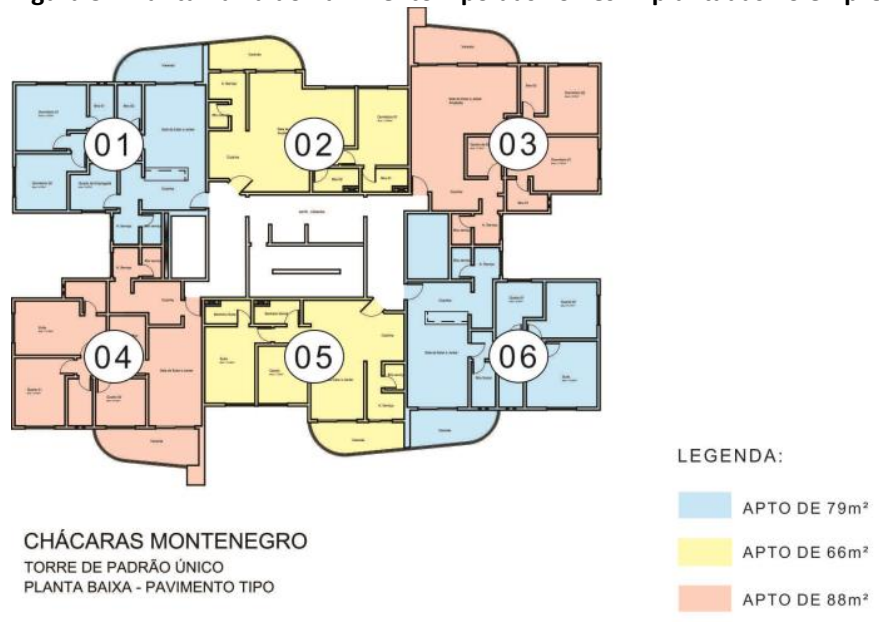

Fonte: elaborado pelos autores a partir de arquivos de desenhos de plantas baixas dos empreendimentos de Status Construções (2010) e Cyrela Brazil Realty (2011).

Para fins de comparação com a torre de padrão único do CCM, foi utilizada a torre que contém unidades habitacionais de $92 \mathrm{~m}^{2}$ e $66 \mathrm{~m}^{2}$ do Subcondomínio Parque Jardins. O pavimento tipo dessa torre possui três elevadores e oito unidades habitacionais, sendo quatro de $92 \mathrm{~m}^{2}$ e quatro de $66 \mathrm{~m}^{2}$ (Figura 6).

Figura 6 - Planta Baixa do Pavimento Tipo da Torres com unidades habitacionais de $92 \mathrm{~m}^{2}$ e $66 \mathrm{~m}^{2}$ do Subcondomínio Jardim de Provence.
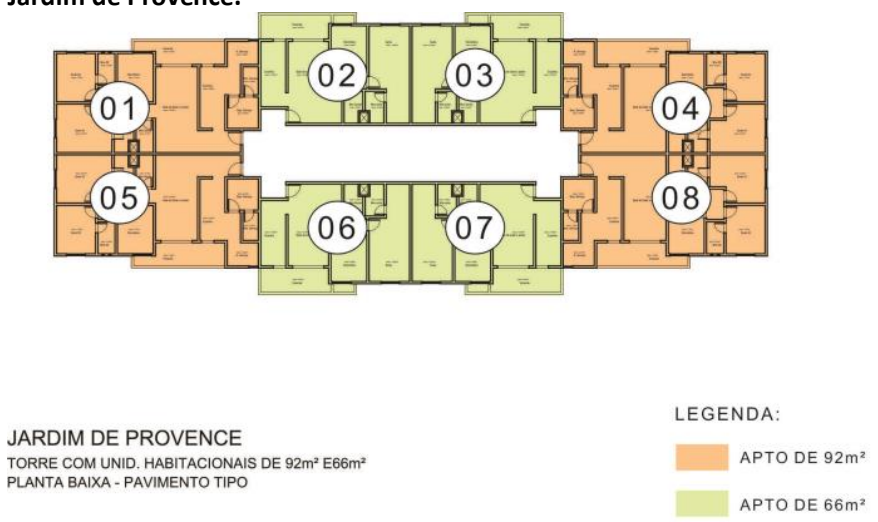

Fonte: elaborado pelos autores a partir de arquivos de desenhos de plantas baixas dos empreendimentos de Status Construções (2010) e Cyrela Brazil Realty (2011).

Observou-se como coincidências que as torres analisadas possuem exatamente a mesma proporção entre a área comum e a área privativa no pavimento tipo (Figura 7).

Ainda nessa escala de análise, uma das variáveis que faria considerável diferença para a rentabilidade de um empreendimento é a relação entre o perímetro da torre e a área dos pavimentos tipo, principalmente em situações nas quais as torres sejam revestidas externamente, o que também é observado em ambos os projetos analisados. Isso porque com um mesmo perímetro é possível abarcar uma quantidade de área variável, conforme é observado no Quadro 5. 
SANTANA, J. M. M. de; LIMA, J. J. F.; VENTURA NETO, R. da S.

Mudanças em projetos arquitetônicos e a financeirização do capital em Belém, PA

Figura 7 - Comparação das proporções entre áreas comuns e privativas dos pavimentos tipos da torre do Subcondomínio Jardim de Provence e da torre do Condomínio Chácaras Montenegro

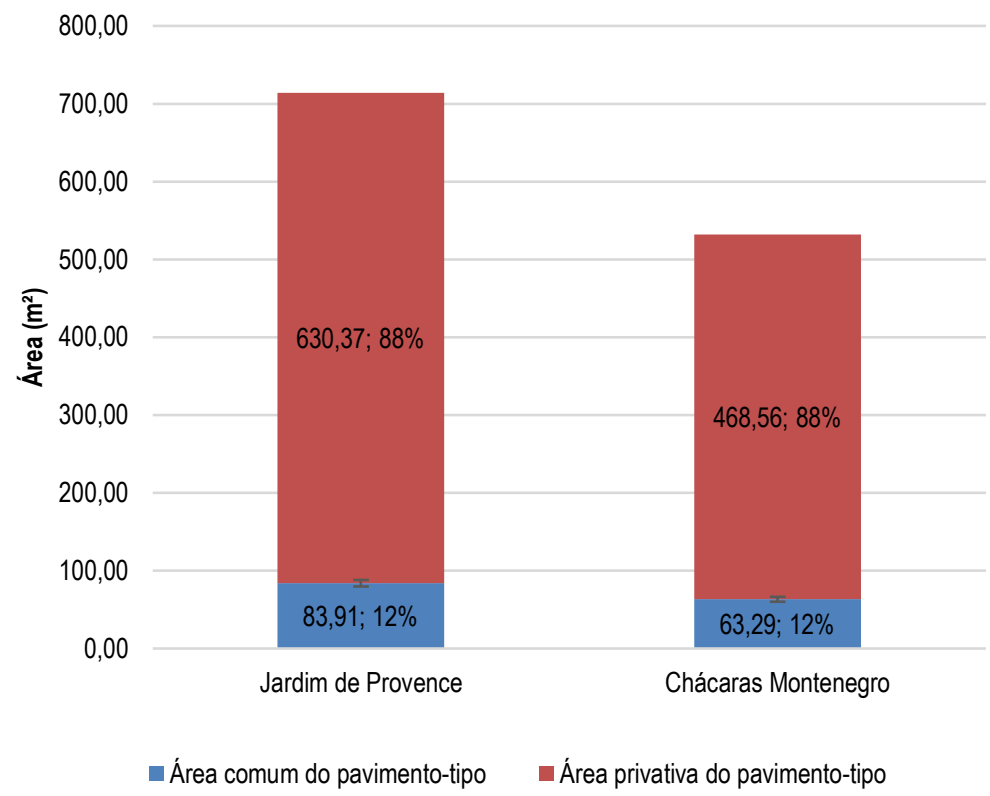

Fonte: medições elaboradas pelos autores, a partir de arquivos de desenhos de plantas baixas dos empreendimentos de Status Construções (2010) e Cyrela Brazil Realty (2011).

Quadro 5 - Relação entre perímetro das torres e área dos seus pavimentos tipo, sem incluir sacadas

\begin{tabular}{|c|c|c|}
\hline \multirow{2}{*}{ Variável } & \multicolumn{2}{|c|}{ Empreendimento } \\
\cline { 2 - 3 } & \multicolumn{2}{|c|}{ Chácaras Montenegro } \\
\hline Área da Torre sem Sacada (m2) & 486,03 & 138,92 \\
\hline Perímetro da Torre sem Sacada (m) & 644,78 \\
\hline Relação entre Perímetro e área das torres (sem sacada) & 131,72 & 3,50 \\
\hline
\end{tabular}

Fonte: medições elaboradas pelos autores, a partir de arquivos de desenhos de plantas baixas dos empreendimentos de Status Construções (2010) e Cyrela Brazil Realty (2011).

Cada unidade de perímetro do projeto da torre do CCM vem acompanhada de $3,5 \mathrm{~m}^{2}$ de área do pavimento tipo, enquanto no Jardim de Provence, cada metro de perímetro vem acompanhado de $4,9 \mathrm{~m}^{2}$ de pavimento-tipo. Levando em conta que ambos os projetos têm a mesma proporção entre área privativa e área de circulação comum, pode-se afirmar que a relação entre perímetro de torre sem sacada e área de pavimento tipo sem sacada é $28,53 \%$ mais eficiente no Projeto do Jardim de Provence, em comparação com o Projeto do CCM no que tange à análise financeira.

Ainda no que se refere à unidade habitacional, também foram encontradas convergências de proporções de áreas nos projetos. Existe forte semelhança entre as proporções de área molhada, área seca e área de varanda de cada um dos tipos de unidade habitacional de ambas as torres analisadas. Conforme pode ser observado na Figura 8 , quase todas as unidades habitacionais tiveram área seca limitada a $66 \%$ da área total, tendo a exceção de $67 \%$ na unidade habitacional de $79 \mathrm{~m}^{2}$ existente na torre de padrão único do CCM. 
SANTANA, J. M. M. de; LIMA, J. J. F.; VENTURA NETO, R. da S.

Mudanças em projetos arquitetônicos e a financeirização do capital em Belém, PA

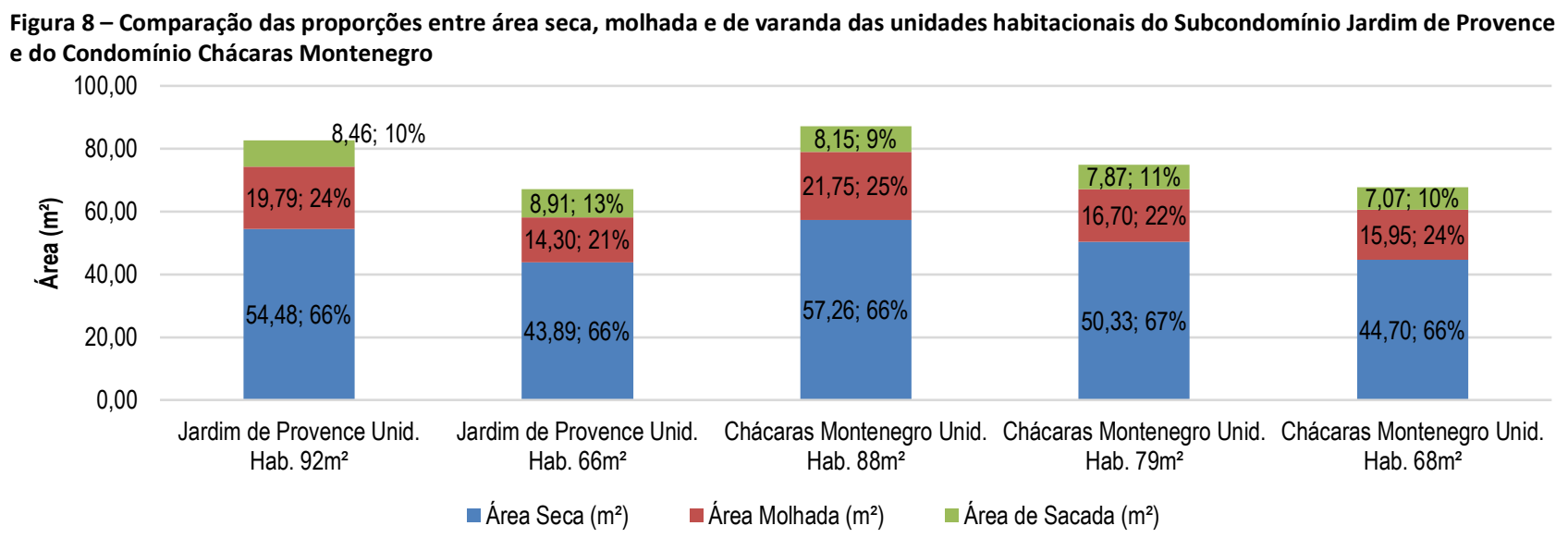

Fonte: medições elaboradas pelos autores, a partir de arquivos de desenhos de plantas baixas dos empreendimentos de Status Construções (2010) e Cyrela Brazil Realty (2011).

Outra congruência existente é a limitação do perímetro de alvenaria revestida internamente nas unidades habitacionais, em relação ao total do perímetro de alvenaria da unidade habitacional. Essa proporção de envoltórias parece ser estabelecida entre 30 e $34 \%$ do total de alvenaria de cada uma das unidades habitacionais (Figura 9).

Figura 9 - Comparação das proporções entre área seca, molhada e de varanda das unidades habitacionais do Subcondomínio Jardim de Provence e do Condomínio Chácaras Montenegro.

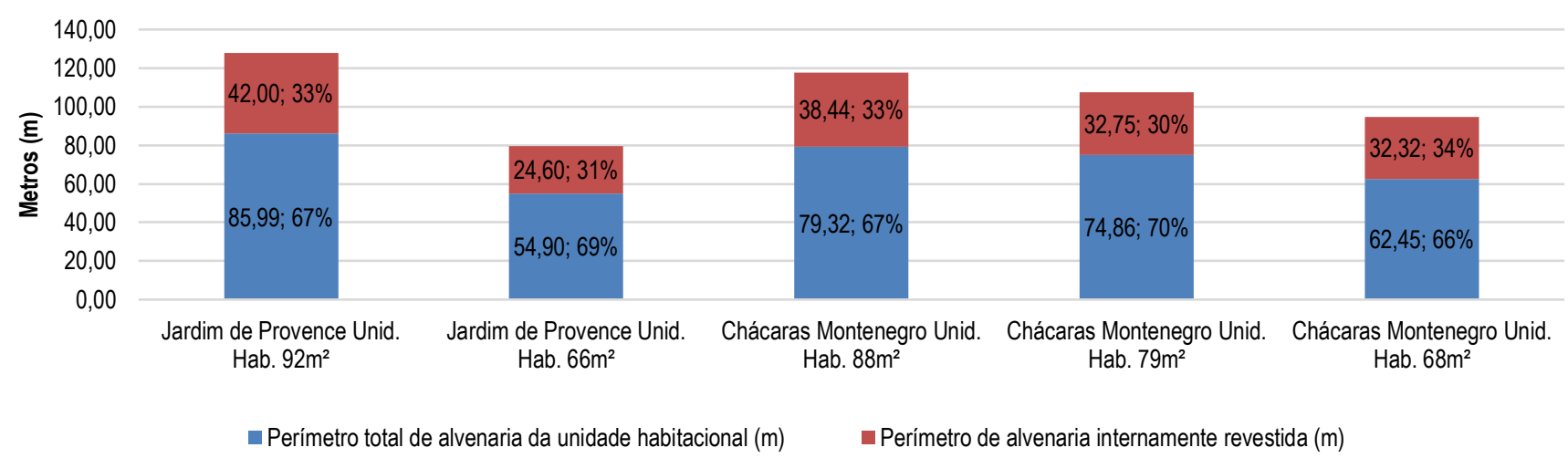

Fonte: medições elaboradas pelos autores, a partir de arquivos de desenhos de plantas baixas dos empreendimentos de Status Construções (2010) e Cyrela Brazil Realty (2011).

\section{Discussão dos resultados}

A percepção da existência de determinadas convergências de proporções métricas nos projetos arquitetônicos dos empreendimentos analisados dá indícios de que não sejam meras coincidências. $O$ fato dos dois empreendimentos possuírem localização, públicoalvo e regimes de incorporação semelhantes possibilita afirmar, com maior segurança, o vínculo dos resultados encontrados com a utilização do Software Viabil, já que ambas as empresas o utilizaram para desenvolvimento das viabilidades econômicas e financeiras dos objetos pesquisados.

A análise dos dados encontrados por meio da mensuração de ambientes e panos de parede e piso nos Projetos Arquitetônicos pesquisados sugere que variáveis, ou relação de variáveis caracterizadas como convergentes, afetam a rentabilidade dos empreendimentos e apresentam-se claramente restringidas pelo Software Viabil, por se tratarem de variáveis e relações mais simples de serem administradas durante o processo de concepção do projeto arquitetônico, o que é estudado por Formoso e Tzorzopoulos (2001). Freitas (2000) e Amato (2009). Isso porque é mais simples 
controlar o pré-dimensionamento durante o processo de concepção de projeto arquitetônico que do perímetro do mesmo, ou alguma relação que o envolva.

A aceitação especificamente do Software Viabil, portanto, está imprimindo determinadas características físicas aos empreendimentos imobiliários, principalmente no que tange à distribuição de área dos ambientes, já que, matematicamente, a manutenção de determinada proporção garante uma viabilidade econômica e financeira positiva, como demonstrou a lógica de tomada de decisão pautada na diferença de custos do metro quadrado construído entre os ambientes da unidade habitacional e na preferência do consumidor em potencial.

Outra convergência entre os empreendimentos analisados - que pode ser atribuída à utilização do software, mas que não está expressa nos resultados - é o fato de ambas as empresas optarem por lançar os empreendimentos em etapas. Essa decisão passou a ser recorrente, inclusive em outros empreendimentos lançados na Área de Expansão municipal, em função de os softwares de viabilidade permitirem a análise financeira de diferentes cronogramas de lançamentos feitos por etapas. É provável que a utilização do software tenha facilitado a percepção de que há ganhos no sistema produtivo pela execução mais rápida, mas também no aproveitamento do terreno e na consolidação da nova localização. Isso ocorre porque, à medida que o cronograma de obras e as entregas vai ocorrendo, o "valor de aglomeração" e a sensação de segurança da entrega contribuem para o crescimento do valor de mercado de venda do imóvel e, consequentemente, da rentabilidade. Ou seja, o empreendimento amplia renda diferencial e de monopólio pelas modificações no entorno associadas à implantação de acessibilidade ao condomínio.

Os resultados evidenciam, portanto, que a utilização do software Viabil com conceitos alinhados pela Metodologia do Custeio-meta, leva, automaticamente, à utilização de indicadores que influenciam no pré-dimensionamento do projeto arquitetônico desses empreendimentos, aspecto que mereceria ser analisado em outras cidades brasileiras.

A influência do mercado financeiro na produção do espaço urbano pode ser percebida por meio da prática de replicação de um mesmo projeto arquitetônico em diferentes regiões do país, realizada tanto por empresas de capital aberto quanto por aquelas incorporadoras de capital local. Este fato pode ser justificado pela necessidade de essas empresas lançarem seus empreendimentos e garantirem valuation (precificação) de suas ações no dia a dia do mercado financeiro. Por meio da reprodução tanto de projetos quanto de planilhas orçamentárias e previsões de lucros facilmente calculados, agiliza-se a geração das Cédulas de Crédito Imobiliário (CCl), que posteriormente podem vir a compor Certificados de Recebíveis Imobiliários (CRI) em uma escala que foge ao escopo deste trabalho. No caso de Belém, a racionalidade financeira teria influenciado o processo de concepção de Projetos Arquitetônicos pelas empresas locais, que embora não sejam exigidos no âmbito da governança corporativa, pelo fato de não se tratar de empresas de capital aberto, ainda assim absorvem tecnologia e acabam por reproduzir uma determinada matriz espacial.

Os dados e as análises de resultados apresentados anteriormente não são as únicas evidências de que um padrão financeirizado de produção do espaço vem sendo construído, independentemente de ser produzido por empresa de capital aberto ou local. Um exemplo disso é a utilização de uma mesma estratégia de criação de centralidade urbana - por meio de rápida articulação entre agentes imobiliários, possibilitada pela recente desregulamentação do mercado imobiliário.

As convergências de variáveis e relações das variáveis apresentadas aqui podem indicar como aquilo que nos últimos anos vem sendo denominado de financeirização pode ter 
a ver com o estabelecimento de um padrão de produção imobiliária fortemente ligado a racionalidades financistas, independentemente da presença, propriamente dita, do capital financeiro.

\section{Considerações finais}

Após a criação de nexo oficial entre o mercado imobiliário e mercado financeiro, viabilizada pela sanção da Lei de Patrimônio de afetação, o setor da construção civil sofreu adaptações de ordem contábil, jurídica e administrativa, com o objetivo de atingir uma gestão compatível com a governança corporativa requerida pelo mercado financeiro. Para que isso fosse possível, as incorporadoras nacionais, que almejavam se alavancar através da abertura de capital na bolsa, engajaram-se no desenvolvimento de planilhas financeiras que facilitassem a gestão de informações vinculadas aos Projetos Arquitetônicos de seus produtos e suas estimativas de custo.

A partir do momento em que o processo de aumento de entrada de capital imobiliário brasileiro permitiu a aceleração do fluxo de capital para outras localidades, por meio da possibilidade de incorporação em regime de Patrimônio de Afetação, as empresas de capital aberto - incluindo a CRB - iniciaram a exploração de outros mercados através de Sociedades de Propósito Específicos realizadas com construtoras locais.

As articulações a partir da ida de empresas de capital aberto a outros mercados e associações com empresas locais trouxeram para as empresas locais modificações na produção, o que pode ser visto nas convergências nos projetos estudados, com a utilização do software Viabil no projeto arquitetônico dos casos de Belém em análise. A empresa de capital local, portanto, reconhecendo a possibilidade de otimização de lucros, começa a utilizar o software mesmo em empreendimentos de capital exclusivamente local, ou seja, teria absorvido inovação advinda de empresas de capital aberto, mesmo sendo de empresas de composição de capital distintas.

O artigo explora os nexos entre métodos de projeto arquitetônico, a desregulamentação brasileira e a entrada do capital financeiro imobiliário, indicando que no caso estudado em Belém, há correspondências entre empresas de capitais com origens distintas ao estabelecerem critérios para projetos arquitetônicos multifamiliares em área de expansão urbana. Ao trazer o caso da Área de Expansão de Belém, o artigo contribui para o entendimento do que seria o reflexo ou o alcance geográfico da financeirização observada e, com menor intensidade, do que ocorreu nas grandes cidades brasileiras. A rigor, não poderíamos tratar de uma financeirização do capital imobiliário em sua completude, uma vez que há limites impostos pelo tamanho da economia local, uma demanda não consolidada e a inexistência de localizações com infraestruturas "prontas" para receber os empreendimentos imobiliários. Isso é algo que justamente indica a magnitude das alterações trazidas para o espaço urbano de cidades da escala de Belém.

\section{Agradecimentos}

Os autores agradecem ao Prof. Dr. Eduardo Nobre do PPGAU USP pela participação em banca de julgamento de dissertação. Ao CNPq pelo apoio no âmbito dos Projetos Perspectivas de Cidade e Cidade em Perspectiva: Desenhos para Belém de 1975 a 2015 (425387/2016-o Universal 01/2016) e Produção e morfologia da expansão urbana na Região Metropolitana de Belém (309087/2018-0 - Bolsas de Produtividade em Pesquisa - PQ)

\section{Notas}

(1) A AV consiste em comparar "o valor entre os diferentes componentes e características de acordo com a sua contribuição para o valor total do produto. Quanto maior o valor da contribuição de uma característica, maior o 
seu custo-alvo. Ou seja, o objetivo é investir mais nas áreas que irão criar valor para o fabricante e reduzir as outras." (BUTSCHER; LAKER, 2000, p.49).

(2) Tradução de "It is the very interconnectedness of all these factors which is the essence of design problems, rather than the isolated factors themselves" (LAWSON, 2005, p. 60).

\section{Referências}

ANITELLI, F.; TRAMONTANO, M. Edifícios de apartamentos, a peça: muda o cenário, mudam os atores mas o roteiro permanece. Cadernos do PROARQ, n. 27, p. 75-88, 2016.

AMATO, F. Implantação de empreendimentos de base imobiliária por meio de fundos de investimento imobiliário: critérios de governança dos recursos financeiros para mitigação de riscos capaz de potencializar a captação de investimentos privados com característica de poupança. 2009. $217 \mathrm{f}$. Tese (Doutorado em Engenharia) - Escola Politécnica, Universidade de São Paulo, São Paulo, 2009.

BARDET, F. ; COULORE, A. ; SHIMBO, L. Financial native: Real estate developers at work. Competition \& Change. v. 24, n. 304, p.203-224. 2020. DOI: https://doi.org/10.1177/1024529420920234.

BADIN, N. T. Modelo de referência para o processo de desenvolvimento de produtos integrando fornecedores e baseado nos conceitos de engenharia simultânea, custeio-alvo e empresa virtual. 2005. $210 \mathrm{f}$. Tese (Doutorado em Engenharia de Produção) - Universidade Federal de Santa Catarina, Florianópolis, 2005.

BUTSCHER, S. A.; LAKER, M. Market driven product development. Marketing Management, v. 9, n. 2, p. 48-53, 2000.

CYRELA BRASIL REALTY. Projeto do Condomínio Parque Jardins. São Paulo: Cyrela Brasil Realty, 2011. 5 p.

FIX, M. A. B. Financeirização e transformações recentes no circuito imobiliário no Brasil. 2011. 263 f. Tese (Doutorado em Economia) - Universidade Estadual de Campinas, Instituto de Economia, Campinas, 2011.

FORMOSO, C. T.; TZORZOPOULOS, P. Gestão da Qualidade na Construção Civil: estratégias e melhorias de processos em empresas de pequeno porte. Porto Alegre: UFRGS, 2001. 354 p.

FREITAS, A. A. F. Segmentação do Mercado Imobiliário Utilizando Dados de Preferência Declarada. 2000. 149f. Tese (Doutorado em Engenharia de Produção) - Universidade de Santa Catarina, Florianópolis, 2000.

FREITAS, T. A. P. A. Muito Prazer! Target Costing. In: CONGRESSO USP DE CONTROLADORIA E CONTABILIDADE, 4., São Paulo, 2004. Anais [...]. São Paulo: USP, 2004.

KLINK, J.; SOUZA, M. B. Financeirizacão, conceitos, experiências e a relevância para o campo do planejamento urbano brasileiro. Cadernos Metrópole, v. 19, n. 39, pp. 379-406, 2017.

LAWSON, B. How designers think. 4. ed. Oxford: Architectural Press, 2005. 335 p.

LEE, John Y. Use target costing to improve your bottom-line. The CPA Journal, New York, Jan. 1994.

LIMA JÚNIOR, J. R.; MONETTI, E.; DE ALENCAR, C. T. Real Estate: fundamentos para análise de investimentos. Rio de Janeiro: Elsevier Editora Ltda., 2011. 456 p.

ONO, K. Utilização do “Target Costing”: Um Estudo Exploratório em um Município de Santa Catarina. 2003.164 f. Dissertação (Mestrado em Controladoria e Contabilidade) - Faculdade de Economia, Administração e Contabilidade da Universidade de São Paulo, São Paulo, 2003. 
RIBEIRO, L. Q.; DINIZ, N. Financeirização, mercantilização e reestruturação espaço-temporal: reflexões a partir do enfoque dos ciclos sistêmicos de acumulação e da teoria do duplo movimento. Cadernos Metrópole, São Paulo, v. 19, n. 39, pp. 351-377, maio/ago. 2017.

ROLNIK, K. Guerra dos lugares. A colonização da terra e da moradia na era das finanças. São Paulo: Boitempo, 2015

ROZENFELD, H. Modelo de Referência para o Desenvolvimento Integrado de Produtos. In: ENCONTRO NACIONAL DE ENGENHARIA DE PRODUÇÃO, 17., Gramado, 1997. Anais [...]. Rio de Janeiro: ABEPRO, 1997.

RUFINO, M. B. C. Incorporação na metrópole: centralização do capital no imobiliário e nova produção do espaço em Fortaleza. 2012. 334 f. Tese (Doutorado em Arquitetura e Urbanismo) - Faculdade de Arquitetura e Urbanismo, Universidade de São Paulo, São Paulo, 2012.

SANFELICI, D. A metrópole sob o ritmo das finanças: implicações socioespaciais da expansão imobiliária no Brasil. 307 f. Tese (Doutorado em Geografia) - Faculdade de Filosofia Letras e Ciências Humanas, Universidade de São Paulo, São Paulo, 2013.

SHIMBO, L. Sobre os capitais que produzem habitação no Brasil. Novos Estudos - Cebrap, São Paulo, n. 105, p. 119133, 2016.

STATUS CONSTRUÇÃO. Desenhos do Condomínio Chácaras Montenegro. Belém: Status Construções, 2010. 10 p.

VENTURA NETO, R. S. Circuito imobiliário e a cidade: coalizões urbanas e dinâmicas de acumulação do capital no espaço intraurbano de Belém. 2012. 239 f. Dissertação (Mestrado em Arquitetura e Urbanismo) - Programa de PósGraduação em Arquitetura e Urbanismo, Universidade Federal do Pará, Belém, 2012.

VIABIL, 2018. Estudo de Viabilidade. Disponível em: <https://www.viabil.com.br/viabil_new_ptbr/viabilidade.asp/>. Acesso em: 23, abril de 2020.

\section{Jayana Marinho Mota de Santana}

Arquiteta e urbanista, mestre em Arquitetura pela Universidade Federal do Pará. Endereço postal: Tv. Dom Romualdo de Seixas, 1500, apto 2502, Umarizal, Belém, PA, Brasil, 66055-200.

\section{José Júlio Ferreira Lima}

Arquiteto, PhD em Arquitetura pela Oxford Brookes University. Professor Titular da Universidade Federal do Pará. Endereço postal: PPGAU UFPA. Prédio das Pós-graduações do ITEC, sala 22. Rua Augusto Correa, no. 1. Campus da UFPA. Belém, PA, Brasil, 66.075-110.

\section{Raul da Silva Ventura Neto}

Arquiteto e urbanista, Doutor em Economia pela Universidade de Campinas. Professor Adjunto da Universidade Federal do Pará. Endereço postal: PPGAU UFPA. Prédio das Pós-graduações do ITEC, sala 22. Rua Augusto Correa, no. 1. Campus da UFPA. Belém, PA, Brasil, 66.075-110. 